\title{
Re-exploring democratic education through virtual learning communities"
}

\author{
Hayriye Tuğba ÖZTÜRK ${ }^{* * *}$
}

\begin{abstract}
Democratic pedagogy has been a concern in education for over a century. Although it has been interpreted in a variety of ways in different epochs, the main underpinning values have remained the same throughout the century. Now, in the information age, there has been considerable debate over whether the technology facilitates the democratization of education. With regard to this, in this article, in the first place, it was aimed to present the democratic education in a historical context, and then the virtual learning communities as a model which has the potential in democratizing the education was discussed. In doing this, a neutral approach was taken and pedagogical challenges were discussed. In reexploring the concept of democratic education, a critical in-depth literature review was taken in an emergent area of educational technology.
\end{abstract}

Keywords: Democratic pedagogy, virtual learning communities, educational technology.

${ }^{*}$ This article is based in part on a chapter in an unpublished PhD thesis (Ozturk, 2011).

* *Dr., Ankara University, Faculty of Educational Sciences, Deparment of Computer and Instructional Technologies Education, Ankara, Turkey. E-mail: tozturk@ankara.edu.tr 


\section{SUMMARY}

Purpose and significance: In this research, it is aimed to examine the concept of democracy in an emergent educational model, the virtual learning communities (VLC). A VLC signifies a democratic learning culture in which a group of individuals come together to work collaboratively and autonomously in a life cycle in order to reach the common aims by utilizing online tools to create a sense of community with shared values. Its underpinning values refer to an ideal model of democracy. Therefore, in this paper, it is aimed to discuss its potential to materialize democratic education in particular through the learning technologies. This study could be helpful to educational designers of emancipated education, and contribute to more collaborative, inclusive decision-making and democratic pedagogy in general in the virtual learning communities; it could also provide an insight into technology use in education.

Method: In re-exploring the concept of democratic education, a critical in-depth literature review was taken in an emergent area of educational technology.

Discussion and Conclusions: In a practical sense, although a VLC offers a democratic pedagogy with its elements such as learning, historicity, identity, mutuality, plurality, autonomy, participation, integration, future and technology (Schwier, 2001: 9), it is important to take into account of the social and epistemological considerations for a meaningful democratic learning as VLCs are embodied in an educational system and the members of VLCs are social entities who are influenced by their social environments through which they form their epistemological stance and learning culture. 


\title{
Demokratik Pedagojinin Sanal Öğrenme Toplulukları ile Yeniden Keşfi ${ }^{*}$
}

\author{
Hayriye Tuğba ÖZTÜRK ${ }^{* *}$
}

ÖZ. Demokratik pedagoji, yüzyılı aşkın bir süredir eğitim alanına konu olmuştur. Farklı dönemlerde çeşitli şekillerde yorumlansa da, özünde yatan değerler hep aynı kalmıştır. Günümüz bilgi çağında ise, teknolojinin demokratik eğitimi destekleyip desteklemediği tartışmaları ile demokratik eğitim yeniden değerlendirilmektedir. Daha spesifik olarak, özellikle internet tabanlı açıköğretim sistemlerinde yaygınlaşan Sanal Öğrenme Toplulukları, kuramsal olarak demokratik oluşumlar olarak varsayılmaktadır ve özellikle teknolojinin sağladığı öğrenme araçları ile tartışılagelen ama günümüze kadar uygulama boyutunda "ideal" olarak kalan demokratik eğitim anlayışını yeniden canlandırmaktadır. Bununla ilgili olarak, bu makalede, önce eğitimde demokrasi kavramının tarihi bağlamdaki gelişimi irdelenerek anlatılmaya çalışılmış ve daha sonra, sanal öğrenme topluluklarının eğitimi demokratikleştirme bakımından potansiyeli olan yeni oluşumlar olup olmayacağı bu makalede ele alınmıştır. Bunu yaparken, nötr bir tutum sergilenip uygulamadaki pedagojik zorluklar dikkate alınmıştır. Demokratik eğitimin teknolojik bir ortamda yeniden keşfini anlatırken, derinlemesine incelemelerde bulunulmuş, eleştirel bir bakış açısı ile alanyazında yer alan ana kuramlar benzerlik ve farklılıkları ile sentezlenerek değerlendirilmiştir.

Anahtar Sözcükler: Demokratik pedagoji, sanal öğrenme toplulukları, eğitim teknolojisi.

\footnotetext{
* Bu çalışma, bir doktora tezinin (Ozturk, 2011) bir bölümünden yararlanılarak hazırlanmıştır. * Dr, Ankara Üniversitesi Eğitim Bilimleri Fakültesi Bilgisayar ve Öğretim Teknolojileri Eğitimi Bölümü Ankara, Türkiye. E-posta: tozturk@ankara.edu.tr
} 


\section{GİRIŞ}

Demokratik pedagoji, eğitimde yer alan bileşenlerin eşitlik çerçevesinde süreci yönlendirdikleri, bilginin uzlaşmaya dayalı olarak yapılandırıldığı ve kolektivist değerlere dayalı olarak yürütülen öğrenme ve öğretim uygulamalarını ifade etmektedir. Demokratik pedagojinin temelini oluşturan değerler eşitlik, özdenetim, farklılıklara ve belirsizliklere rağmen uyumluluk içinde hareket etme olarak ele alınabilir. Ancak bu değerler aynı zamanda demokratik pedagojiyi, uygulamada ütopik kılan değerlerdir. Belki de bu yüzden yüzyılı da aşkın bir süredir tartışma konusu olmuş ancak uygulamada çoğunlukla bir ideal olarak kalmıştır. Ancak şimdi, teknolojisinin işe koşulması ile demokratik pedagoji tartışmaları yeniden canlanmış ve eğitimin teknoloji ile demokratikleştirilmesi konusu araştırmacılar tarafindan farklı şekillerde yorumlanmıştır (Boyd, 1987; Garrison, 1997; Hodgson, 2002; Riel, 1995; Sorensen \& Murchu, 2004). Bu çalışmanın amacı tam da bu noktada teknolojinin eğitimi demokratikleştirip demokratikleştirmediğine dair tartışmaları eleştirel bir bakış açısı ile alanyazına dayalı olarak sunmaktır.

Bunu yaparken, alanda yer alan tartışmalar ana kuramlar çerçevesinde ve bakış açılarındaki farklılık ve benzerlikler ile demokratik eğitimin tarihi gelişimi de dikkate alınarak sunulmaya çalışılmıştır. Aşağıdaki bölümlerde, zaman içerisinde demokratik eğitim ekseninde evrilen kuramsal tartışmalar ve bu kuram çerçevesinde teknoloji bağlamında gelişen yeni yönelimler kısaca belirtilmiştir.

\section{Demokratik Pedagojiye Genel Bir Bakış}

Demokratik pedagoji 1900'lü yılların başında John Dewey ile öne çıkmıştır. Dewey, özgür usların ancak demokratik okullarda serpilen özgür düşünce sistemi ile gerçekleşebileceğini savunmuş (1903) ve demokratik eğitimi okullarda uygulamanın yolunun alan bilgisi, yöntem ve yönetimden geçeceğini belirtmiştir (1916). Buna göre, Demokrasi ve Eğitim adlı kitabında (1916: 212) alan bilgisini "amac1 olan gelişimsel bir durum ile ilgili olarak gözlenilen, hatırlanan, okunan ve konuşulan gerçeklikler, ileri sürülen düşünceler" olarak tanımlamıştır. Yöntem ise alan bilgisini en etkili bir şekilde uygulamaya dönük süreçler olarak ifade edilmiştir. Yöntem, 
öğrencilerin katılımcı demokratik karar alma süreçlerinde aktif olarak yer almalarını destekleyici nitelikte olmalıdır. Dewey'e göre alan bilgisi ve yöntem iç içedir ve birbirlerini etkilemektedir. Bu noktadan yola çıkarak, eğitim yönetiminin iki boyutu vardır: öğrenme sürecinin düzenlenmesi (yöntem) ve öğretilecek içerik (alan bilgisi). Kısaca, bu yaklaşıma göre, öğrenciler kendi deneyimlerinden ve alan bilgilerinden faydalanarak kendilerine özgü bilgiyi oluşturmalıdırlar.

Ancak, Dewey'in demokratik eğitimi öne çıkaran bu görüşleri her ne kadar o dönemde Kuzey Amerika'daki eğitim sisteminde yaygın bir şekilde kabul görmemiş olsa da Dewey'in günümüz demokratik eğitim tartışmalarına yön veren alanyazına katkısı oldukça önemlidir.

Dewey'in düşüncelerine paralel olarak bir demokratik eğitim uygulaması da 1920'li yıllarda İngiltere'de görülmektedir. Ancak belirtmek gerekir ki bu uygulamalar ana akım eğitim sisteminin bir parçası olmayıp ancak sınırlı düzeyde birkaç uygulamayı kapsamaktadır. 1921 yılında A.S. Neill, "ana fikir çocukları okula uydurmaktansa okulları çocuklara uydurmaktı" söylemleri ile Summerhill okulunu açmıştır (Neill, 1961:20). Bu söylemi hayata geçirmenin bir yolu olarak düzenli yapılan toplantılarda öğrencilere okul yönetiminde söz hakkı tanınmıştır. Bu uygulamanın bir gerekçesi olarak, Neill şunları söylemektedir: "Demokrasi oy verme yaşını yani 21 yaşını beklememelidir, beklerse bu demokrasi olmaz; oy vermek için on binde bir olmak demokrasi değildir" (1992:23). Summerhill okulunda eşit katılım haklarına ilaveten, özyönetim de mutlak bir değerdir. Bunun bir örneği olarak, öğrenciler istemedikçe derse girmemişlerdir. Çünkü özyönetim anlayışı dışarıdan bir otorite olmadan özgür irade hakkını bireylere tanır (Neill, 1992).

$\mathrm{Bu}$ demokratik ilkeler eğitim bileşenlerinin pratiklerine nasıl yansımaktadır? 1949 yılında İngiltere hükümeti tarafından Summerhill okuluna gönderilen müfettişlerin kaleme aldığı resmi rapora göre (Neill, 1992) dersler zorunlu olmasa da öğrencilerin çoğu gönüllü olarak derslere katılmıştır. Bu öğrenciler, sadece alan bilgisine yönelik dersler değil aynı zamanda sanat, yaratıcı düşünme, beden eğitimi gibi dersleri de almışlardır ve aldıkları bu derslerde gösterdikleri başarılar müfettişleri etkilemiştir. Bu teftiş raporunda bir de derslere yıllarca katılmayan bir öğrenciye de değinilmiştir. $\mathrm{Bu}$ öğrenci, derslere hiç katılmasa da kendini alet yapımı konusunda geliştirmiştir. Müfettişler, raporlarında bu uygulamalara gönderme yaparak "özgürlük gerçek" 
ifadesini kullanmışlardır. Ancak, genel olarak değerlendirdiklerinde sistemde yetersizlikler de görülmüştür. Bu yetersizlikler üç kategoride ele alınmıştır: 1) yardımcı öğretmenlerin eksikliği 2) öğrencilerin yetersiz yönlendirilmesi 3) sessiz çalışılabilecek bir oda ve öğrencilerin kendilerine ait özel odaları olmadığı için gizlilik ihlali.

Diğer bir eğitim bileşeni olan öğretmenlere gelince, öğretmenler akademik y1l için belirlenen zaman çizelgesine uymakta olup kendilerinden beklenilen özel bir öğretim yöntemi bulunmamaktadır. Öğretmenler de, müdür ve öğrenciler ile birlikte okul yönetimine eşit olarak katılmaktadırlar.

Yukarıda, Dewey ve Neill tarafından öne çıkarılan iki demokratik eğitim uygulaması örneğine değinilmiştir. Ancak, dikkate almak gerekir ki hem Dewey hem de Neill çalışmalarını ilkokul öğrencileri üzerine odaklamışlardır. Oysa demokratik eğitimin, sadece belirli yaş grubuna hitap eden eğitimi değil tüm eğitim kademelerini ilgilendirdiği düşünüldügünde genel olarak demokratik eğitimi anlamak açısından Neill'in ve Dewey'in çalışmalarının sınırlı kaldığı görülmektedir. Ayrıca, 1900'lü yılların başlarında etkili olan değerler sistemi dikkate alındığında (örneğin yönlendirmeci, öğretmen odaklı, sert cezaların verildiği) demokratik eğitim o dönemlerde sadece "ideal” düzeyinde kalmıştır.

1970'li yıllara gelindiğinde ise, radikal demokrasi ve feminizm, sosyal adalet gibi diğer sosyal hareketlenmeler demokratik eğitim ile benzer kaygıları taşıyan eleştirel pedagojinin ortaya çıkmasında bir iç dinamik yaratmıştır. Bu alanın öncülerinden olan Paulo Freire (1970; 1998) eğitim ve ideoloji arasındaki ilişkiye vurgu yapmıştır. Giroux (2007) eleştirel pedagojiyi demokrasinin yaşamsal bir parçası olarak görmüş ve bunu gerçekleştirmenin bir yolu olarak öğrencilerin sadece yönetenler değil aynı zamanda yönetme kapasitesi olan bireyler olmaları gerektiğini öne sürmüştür.

Yakın zamana gelindiğinde ise Pearl ve Knight (2000: 198) demokratik eğitimin yedi özelliğini aşağıdaki gibi sıralamışlardır:

1. Önemli bilgiye karar verilmesi

2. Ĕgitim otoritesi

3. Üyelerin sürece dâhil edilmesi ve sıralama

4. Hakların tanımlanması ve kullanılması

5. Başkasının hayatını etkileyebilecek karar alma süreçlerine kat1lim

6. Eşitlik

7. Optimal öğrenme çevresi 
Pearl ve Knight'a göre bu karakteristiklerin açımlanması şu şekildedir:

(1) Önemli bilgiye karar verilmesi. Yazarlar, burada bilginin ontolojisine "okullarda okutulan önemli bilgiye kim karar vermektedir" sorusunu sorarak vurgu yapmaktadır. Buna göre, önemli bilgiye karar verilirken otorite anlayışına bakılmaksızın hangi bilginin önemli olduğu ve okutulması gerektiğine herkes demokratik katılım ile karar vermelidir. Örneğin, öğrenciler kendi hayatlarını etkileyecek olan bilgiye karar verme aşamasında yer almalıdırlar.

(2) Eğitim otoritesi. Eğitim katılımcı bir süreci gerektirmelidir ve ayrıcalıklı epistemolojik pozisyonda olan bir bilgi otoritesi olmamalidir.

(3) Üyelerin sürece dâhil edilmesi ve sıralama. Eğitim bileşenleri farklı karakteristikte olabilirler veya farklı kültürlerden ve sosyoekonomik düzeylerden gelmiş olabilirler. $\mathrm{Bu}$ şekilde değerlendirildiğinde, eğitim herkesi bünyesinde barındıracak şekilde kapsamlı olmalıdır. Aksi halde, bileşenler arasında anlamlı bir iletişimin gerçekleşmesi engellenmiş olabilir.

(4) Hakların tanımlanması ve kullanılması. Eğitimde yer alan herkesin hakları vardır ve herkes bu haklar ile korunur. Temel olarak, Knight ve Pearl (2000) dört tür demokratik haktan bahsetmektedir: 1 . Kendini ifade etme hakkı 2. Gizlilik hakkı 3.Bağımsız bir şekilde yargilanma hakk1 ve korunma 4. Hareket hakk1

(5) Başkasının hayatını etkileyebilecek karar alma süreçlerine katılım. Yazarlar, Goethe'nin "işe yaramaz bir hayat erken ölümdür" sözünden alıntı yaparak okulların bireyleri yaşama hazırlama işlevlerinden bahsetmektedirler. Bireyler bu yüzden eğitimde karar alma süreçlerine katılmalıdırlar ve belki de bu sayede kendilerini okula ait görebilirler. Bu tür süreçlere katılım, okulları bireylerin gelecekleri için önemli bir yere taşıyacaktır.

(6) Eşitlik. Eşitlik demokrasinin en önemli bileşenlerindendir. Her ne kadar eşitlik her bir birey temelinde gerçekleştirilmesi zor bir bileşen de olsa, eşitlik hedefleyen bir demokrasi için çabalamak gerçekçi bir kaygı olarak görülebilecektir.

(7) Optimal öğrenme çevresi. Demokratik sınıfların var olması için onların oluşumuna sebep olabilecek koşulların sağlanması gerekmektedir. Kısaca, Knight ve Pearl'e (2000) göre bu koşullar bileşenlerin risk almalarını cesaretlendirerek, çeşitli rahatsızlıkları 
ortadan kaldırarak, anlamlandırarak, onların yeterlilik, aidiyet, yararlı hissetme, umut, heyecan, yaratıcılık ve eğitimi sahiplenme duygularını geliştirerek sağlanabilir.

Demokratik pedagojinin özelliklerini tanımladıktan sonra bir diğer önemli nokta da bu özelliklerin zorunlu eğitime nasıl uygulanabileceğidir. Özellikle, özerk öğretim pratikleri zorunlu öğretimde birçok açıdan çelişkili durumlar yaratabilmektedir. Örneğin, demokratik eğitime göre yarı-yapılandırılmış öğretim programı yürürlükte olan ulusal müfredat ile çelişkili olabilir. $\mathrm{Bu}$ noktada, Boud (1988) yüksek öğretimde üç özerk uygulama boyutuna değinmiştir: eğitimin hedefi, özerk öğretim yöntemi ve alan bilgisi ile ilgili özerklik. Kısaca, eğitim hedefi boyutu ideal insan davranışlarını, özerk ögretim yöntemleri bireylerin karar alma süreçlerinde sorumluluk hissetmelerine yönelik ve öğrenenlerin bağımsızlığını cesaretlendirecek yaklaşımları ve son olarak alan bilgisi ise öğrencilerin eleştirel ve bağımsız düşünebilme yeteneklerini geliştirecek bilgileri simgelemektedir. Boud (1988) aynı zamanda yüksek öğretimde özerk öğretim yaklaşımlarını birey merkezli, grup merkezli ve proje merkezli yaklaşımlar olarak özetlemektedir. Birey merkezli yaklaşımda öğrenenler kendi ihtiyaçlarını ve öğrenme sürecini belirlerken, grup merkezli yaklaşımda odak bireyin öğrenmesinden grubun öğrenmesine kaymıştır. Boud'un (1988: 25) ifadesi ile: "diğerlerinin desteği ve geribildirimleri ve de girişimciliğ için bireyler kendi öğrenme ihtiyaçlarını grup bağlamında takip ederler". Demokratik karar alma süreci grup tartışmaları içinde yerini bulur. Son olarak, proje merkezli yaklaşımda belirli bir proje ve proje çıktısı esas alınır. Projeler aracılığı ile öğrenenler durumlu etkinliklere ve öğrenme pratiklerine aktif olarak katılırlar.

Genel olarak, sunulan bütün bu tartışmalara bakıldığında, demokratik eğitim 1900'lü yılların başında, 1970'lerde ve 1980'li dönemlerde farklı düşünürlerce benzer özellikler ile tanımlanmıştır. Dewey, Neill ve de Knight ve Pearl ortak olarak demokratik eğitimin karakteristikleri olarak bilginin özgünlügüne, özdenetime, çoğulculuğa, katılım ve eşitliğe değinmiştir. Ancak her ne kadar benzer değerler üzerine bir yüzyıl boyunca tartışılsa da, bu paradigma uygulamada çoğunlukla “ideal” olarak kalmıştır. 2000'li yıllara gelindiğinde ise özellikle uygulama boyutunda teknolojinin eğitimi demokratikleştirebileceğine dair görüşler ile demokratik eğitim 
anlayışı yeniden canlanmıştır. İlerleyen bölümlerde, bu çalışmanın odağı bahsedilen teknolojik gelişmeler bağlamında "Sanal Öğrenme Toplukları" ile sinırlandırılıp, bu topluluklar üzerinden demokratik eğitim tartışmalarına yer verilecektir.

\section{Sanal Öğrenme Toplulukları (SÖT) ve Demokrasi}

Sanal öğrenme toplulukları ve demokrasi ilişkisini tartışmadan önce, bu oluşumun ne olduğunu ve hangi özellikleri ile demokratik olup olamayacaklarını temel düzeyde ele almakta fayda vardır.

\section{Sanal Öğrenme Topluluklart}

Sanal öğrenme topluluğu, öğretmen ve öğrencilerin içerik ve de dersin akışının planlanmasında, uygulanmasında ve değerlendirilmesinde eşit sorumluluk aldığ , düşüncelerin paylaşıldığı işbirlikli öğrenme tasarımlarının ileri düzeyde yorumlanmasıdır (Hodgson \& Reynolds, 2005: 15).

Schwier (2001) SÖT'lerin kuramsallaşmasında bileşen, amaç ve topluluğu harekete geçirici etmenler (Catalysis) konularına vurgu yapmıştır. SÖT'lerin bileşenleri topluluk üyelerini bir araya getiren değerleri kapsar. Amacl ise topluluk üyelerinin farklı öğrenme amaçlarını temsil eder. Son olarak, topluluğu harekete geçirici etmenler topluluğun gelişimini canlandıran etkinliklerdir. Bu öğelerin daha ayrıntılı açıklamaları aşağıdaki şekilde (Şekil 1) görülebilir.

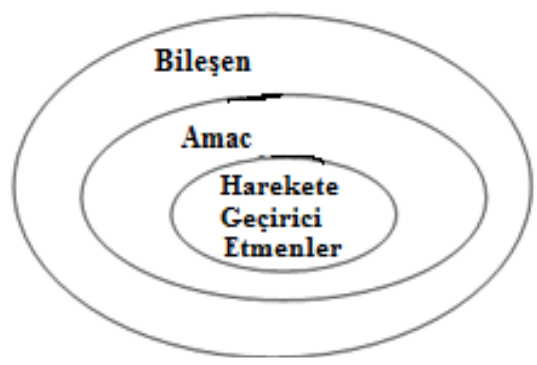

SÖT bilesenleri: Öğrenme, geçmiş, kimlik, karşıliklilik, çoğulculuk, özerklik, katılım, kaynaştırma gelecek, teknoloji

Amac: ilişkiler, mekan, düşünce, tören, fikirler

Topluluğu harekete gecirici etmenler: etkileşim, müdahil olma, uyum

Şekil1. Bir sanal öğrenme topluluğunun öğeleri (Schwier, 2001: 9). 


\section{SÖT'lerin bileşenleri}

Yukarıdaki şekilden de (Şekil 1) görülebileceği gibi SÖT'ler demokratik eğitimin karakteristiklerini barındıran özerklik, çoğulculuk ve katılım gibi bileşenlere sahiptir. $\mathrm{Bu}$ bileşenlere ayrıntısı ile bakıldığında:

Öğrenme: Öğrenme SÖT’leri bir araya getiren asıl neden olduğu için SÖT'lerin oluşumunda da birincil öneme sahiptir. Bütün öğrenenler, sürece katkı sağlamaları konusunda teşvik edilir.

Geçmiş: SÖT üyeleri, topluluğun varlığını tarihi bir döngüde devam ettirir. Geçmiş, şimdi ve gelecek gibi tarihi döngüde var olmak aynı zamanda topluluk üyelerinin katılımını daha anlamlı hale getirir.

Kimlik: Kimlik, üyelerin topluluğa bağlılık durumlarını ve de topluluğun sınırlarını (tanımlanan odağı) simgeler. Zaman içerisinde hem bireyler hem de topluluk kimlik geliştirebilir. İdeal bir SÖT farklı kimlikleri bünyesinde barındırabilmelidir.

Karşıllıklılık: Karşılıklılık topluluk üyelerinin ortak anlamı yapılandırırken birbirine bağlı olmalarını ve mütekabiliyeti simgelemektedir. $\mathrm{Bu}$ bileşen, "amacı ve niyeti yapılandırma ve etkileşim türlerini”" kapsar (Schwier, 2007: 41).

Çoğulculuk: Çoğulculuk, topluluk içindeki farklı görüşleri ve bireysel farklılıkları simgeler; bu sayede topluluk üyelerinin öğrenme deneyimi zenginleşir ve canlılık kazanır.

Özerklik: Topluluk üyelerinin kendilerini özgürce ifade etme kapasitesini ve ortak anlamda uzlaşmayı simgeler. Bu aynı zamanda, öğrenenlerin kendi iradeleri ile ceza almadan çekilebilecekleri bir sisteme de işaret eder. Özerklik sayesinde, üyeler kimliklerini korurlar, fikirlerini ifade edebilirler ve bireysel farklıkları ile kendilerini var edebilirler. Öğrenme sürecinde etkileşim, katılımdan ve de değişen güç ilişkilerinden doğar.

Kaynaşma: $\mathrm{Bu}$ bileşen, SÖT bileşenlerinin bir birine kaynaşması durumunu ifade eder. Kaynaşma, topluluğu destekleyici değerler ile özdeşleşmiştir. Schwier'e göre (2011: 12) bu bileşenin bir uygulama örneği olarak, topluluk üyeleri "inanç sistemlerini ifade edebilirler ve topluluk geliştikçe grup normlarını belirleyebilirler".

Katılım: Katılım, SÖT'de üyelerin sürece katkısını gerektiren en önemli bileşenlerdendir (Lewis \& Allan, 2005; McConnell, 2006; 
Schwier, 2001; Wenger, 1998). İşbirlikli bir ortamda katılım birlikte çalışıyor olmanın bir göstergesidir (Dillenbourg, 1999: 9).

Teknoloji: Katılım gibi teknoloji bileşeni de SÖT'ler için önemli bir yere sahiptir. Teknoloji, topluluğun oluşumu ve bir araya gelmesi için bir alan, gelişimi için bir ortam sağlar.

\section{Amaç}

SÖT'ler ortak bir amacı gerçekleştirme gayesi ile oluşmuştur. Ortak amaç üzerine kurulu olan bir toplulukta, Schwier (2001) beş noktaya değinmiştir: ilişkiler, mekân, düşünce, tören ve fikirler.

Topluluk bir mekân dâhilinde kuruludur ve bu alan üyelere güvenlik hissi vermenin yanı sıra ortak özelliklerin paylaşılabileceği ve miras bırakılabileceği bir platform sağlar (Kowch \& Schwier, 1997).

Hodgson'a göre (2008), çevrimiçi öğrenme toplulukları, üyelerin ikamet ettikleri ve aynı zamanda bireysel ve kolektif kimliklerin yapılandırıldığ 1 bir öğrenme alanı olarak değerlendirilebilir. Burada SÖT'leri tanımlamada yardımcı olabilecek iki vurgu vardır: kimlik yapılandırması ve öğrenme alanları. Kimlik yapılandırması, özellikle herhangi bir grup ile karşılaştırıldığında SÖT'lerin ayırt edici özelliklerindendir. Örneğin bir gruba aidiyet hissi ve de kimliğini bu çerçevede yaşatma durumu toplulukları gruptan ayıran özelliklerdendir. İkinci vurgu olan öğrenme alanları ile anlatılmak istenilen fiziki bir alandan çok, üyelerin paylaşılan sosyal pratikleridir (Hine, 2000; Jones, 1995; Watson 1997).

Bir diğer amaç öğesi de fikirlerdir. Diğer topluluk türlerinden farklı olarak, fikir toplulukları belirli bir öğrenme hedefi üzerine odaklanır ve genellikle başarı veya ürün odaklı topluluklar olarak nitelendirilirler.

Son olarak, tören, topluluğun ritüellerini ve önemli tarihlerini simgeler. Schwier'in (2001: 17) cümleleri ile "bu topluluklar şu açıdan törenseldir ki amaçlar ritüellere veya yüksek derecede onlarla özdeşleşmiş kişisel kimlik saptamaya yönelik daha büyük varlıklar ile bağlanmıştır". 


\section{Topluluğu Harekete Geçirici Etmenler}

Schwier'e (2001) göre topluluğu harekete geçirici etmenler SÖT'lerin gelişimini desteklemesi açısından önemlidir. Bu etmenler, iletişim, müdahil olma ve uyum durumlarını kapsamaktadır. Öğrenme süreci, iletişim ile başlar ve daha sonra etkileşim ve uyum etmenlerini harekete geçirir. Bu öğrenme kültürü, "sürekli öğrenme normlarını ve geliştirmeyi; diğerlerinin öğrenmesinin sorumluluğunu üstlenmeyi; işbirliğine dayalı meslektaş ilişkilerini” hedefler (Ford ve diğerleri, 2008: 165) ki bunlar da topluluğun ortak amacına ulaşmasını kolaylaştırır.

\section{Sanal Öğrenme Topluluklarının Demokratik Pedagoji Açısından Sorgulanması}

Yukarıda da değinildiği gibi, SÖT'lerin pedagojik değerleri bilginin özgünlüğü, özdenetim, çoğulculuk, katılım ve eşitlik gibi temel demokrasi bileşenleri ile şekillenmiştir. $\mathrm{Bu}$ anlamda, özellikle son dönemlerde internet tabanlı açıköğretim sistemlerinde yerini yaygınlaşarak alan SÖT'ler eğitimi demokratikleştirme bağlamında bir potansiyel arz etmektedir. Ancak, öğrenmenin sosyal boyutunu dikkate almadan özellikle teknolojinin eğitimi demokratikleştirebileceğini varsaymak determinist bir yaklaşım sergilemek anlamına gelecektir. Bu yüzden, eleştirel bir bakış açısı ile bu konuyu irdelemek gerekir. Buna dayalı olarak, alanyazında SÖT'lerin bazı bileşenlerinin uygulamadaki karşılıklarının günümüzde de problematik olabileceğine işaret eden eleştirel yaklaşımlar mevcuttur (Levy, 2004; Mantovani, 1994; Öztürk, 2011).

Daha önceki bölümlerde özerklik bileşenine değinilmiş ve bileşenlerin özerk olmalarının zorunlu eğitimin gerçeklikleri ile nasıl çelişebileceğinden bahsedilmiştir. Bu tartışmalar, Boud'un (1988) yüksek öğretim kapsamında olası çözüm alternatifleri ile genişletilmiştir.

Bir diğer nokta da sanal öğrenme topluluklarının karşılıklılık bileşeni ile ilgilidir. Karşılıklılık diğer öğrenenler ile birbirine bağlılık anlamına gelmektedir ve bu da güven duygusu ile gerçekleşebilir. Smith (2008) ve Bruffee (1999) de bu noktada topluluk üyelerinin birbirlerinin öğrenmelerine karşı güven hissetmeleri ve akran 
öğrenmesinin sorumluluğunu almaları gerektiğini ifade etmişlerdir. Ancak bu kolayca başarılabilecek bir durum olmayıp topluğun öğrenme sürecinde bir sorun teşkil edebilmektedir.

Son olarak, bazı araştırmacılar (Cooked \& Kothari, 2001; Ferreday \& Hodgson, 2010; Pedler, 1981) SÖT'lerin bir gerekliliği olan katılım öğesine dikkatleri çekmek istemiştir. Örneğin Ferreday ve Hodgson'a göre (2010: parag. 2) her ne kadar "öğrenmede katılımcılık pedagojik açıdan etkili" bir yöntem de olsa, "dönüşümsellik olmadan gerçekleştirilen katılım sadece baskıcı değil aynı zamanda çoğunluğun tiranlığına da vesile olabilir". Pedler (1981) de benzer konulara değinmiş ve özellikle yönlendirmeci pedagojilerde çoğunluğun belirlediği hedeflerin kişisel anlamlı öğrenmenin önüne geçebileceğini belirtmiştir.

Öğrenme topluluklarının sanal boyutunu, pedagojinin var edilmesine ve öğrenme topluluklarına platform sağlanmasına yarayan teknolojiler oluşturmaktadır. Teknolojiler ve teknolojilerin eğitimi demokratikleştirmesi konusunda, alanyazında gittikçe artan sayıda araştırmalar yer almaktadır (Boyd, 1987; Garrison, 1997; Riel, 1995; Sorensen \& Murchu, 2004).

Lankshear ve diğerleri (1996: 160) bu konuda şunları ifade etmiştir: "Pedagoglar, öğretmen, yönetici ve öğrencilere atanan rolleri değiştirme gücü olan 'bağlantılar' ve 'ağlar' kavramları ile öğrenme ve öğretimi yeniden düzenlemelidirler. $\mathrm{Bu}$ noktada, sanal toplulukların daha demokratik bir eğitimi gerçekleştirmek için potansiyelleri vardır".

Daha spesifik olarak, Garrison (1997) teknolojinin öğrenenler arasındaki etkileşimi güçlendirerek anlamın sosyal yapılandırmasını desteklemekte ve ortak anlayışı güçlendirmek için bir potansiyel arz etmekte olduğunu belirmektedir. Buna göre, öğrenme teknolojileri öğrencilerin rahatlıkla kaynak ve materyal paylaşabildikleri bir ortam sunmaktadır. Bunun yanı sıra, teknolojik araçlar öğrenenleri hem birbirine hem de kaynaklara bağlayabilmektedir. Bunun somut bir örneği olarak, videokonferans sistemi ile öğrenenler arasındaki sosyal bağ güçlenebilir, çift yönlü iletişim sağlanabilir ve bu ise eğitimde diyaloğu artırıcı bir özellik olarak değerlendirilebilir.

Buna paralel olarak, Habermas'ın söylemlerinden yola çıkarak, Boyd da (1987: 167) şunları söylemektedir: "Okullarda kullanılan geleneksel medya iletişim araçları uyumluluğa (tekdüzeliğe) 
yönlendirmektedir. Ancak, Habermas'ın bahsettiği özgürlük söyleminin kriterleri ile bilgisayar destekli konferans yönteminin temel özellikleri çok yakındır ve bu olanaklar eğitime bir ortam sağlamaktadır”. Boyd (1987: 168) makalesinde bilgisayar destekli iletişim araçlarının "baskın faktörleri azaltabilecek ve sözel dağınıklık ile retorik hilelerin önüne geçebilecek liberal söylemlerin" oluşmasında ideal koşulları sağlayabilecek araçlar olduğunu belirtmiştir.

Ancak bazı araştırmacılar, teknolojiyi mutlak olarak eğitimde demokratikleşmeyi sağlayacak araçlar olarak değerlendiren görüşlere eleştirel bakmaktadırlar. Mantovani (1994) teknolojinin tek başına sosyal eşitsizlik gibi bazı temel sosyal problemleri çözmeye yetmeyeceğini, aslında bu araçların bağımsız değil, tam tersine sosyoteknik ağlara kaynaştırıldıklarını belirtmiştir. Mantovani (1994: 14) şunları ileri sürmektedir: "Kurumlardaki iletişim ve statü farklılıklarındaki bariyerler açıkça teknik bir konudan ziyade daha çok sosyal konulardır ve bu sosyal eşitsizliklere çözüm getirmek için düşünülen teknoloji arayışı ancak safça bir duruş olarak görülmektedir".

Benzer bir biçimde, Levy (2004: 51) teknolojiye deterministik yaklaşan araştırmaları sorgulayan çalışmaların arttığına dikkat çekmiş ve şöyle eklemiştir: "Önceden var olan sosyal siniflandırmalar ve normlar çevrimiçi ortamlardaki sosyal buradalık ve kimliği yapılandıracaktır ve bu yüzden (teknolojinin) demokratik kuramı gerçekleştirme konusundaki işlevi fazlasıyla deterministik bir yaklaşım olarak değerlendirilebilir".

Bir başka eleştirel yaklaşım ise, sanal öğrenme topluluklarının 'ağ' ve 'bağlantı' yapısına yöneliktir. Her ne kadar Lankshear ve diğerleri'nin (1996) üzerinde durduğu gibi ağların ve bağlantıların öğrenme ve öğretimi yeniden düzenleyici yönde etkileri de olsa ve de merkezi bir sistem üzerinden dağıtık yapıdaki sosyal bağları güçlendirse de teknik özellikleri gereği ağlar üzerinde yapılan işlemlerin, yazışmaların ve etkinliklerin kayıt altında tutulması mümkündür. $\mathrm{Bu}$ ise çeşitli şekillerde gözetlemeye (surveillance) dayalı denetim ve kontrol mekanizmalarını harekete geçirebilir (Conlon, 2000; Warschauer \& Lepeintre, 1997) ve dolayısiyla sanal öğrenme topluluklarının bağımsız ve özerk yapısını sorgulatıcı bir durum oluşabilir. 
Son olarak, Öztürk (2011) sanal öğrenme topluluğu tasarım ilkelerine dayalı olarak tasarımladığı bir dersin sonuçlarını yaptığ çalışması ile paylaşmaktadır. Buna göre, her ne kadar SÖT bir anlamda demokratikleştirmeye öncülük etse de, tasarım aşamasında dikkate alınmayan bazı sosyo-epistemolojik faktörler öğrencilerin demokratik eğitim deneyimlerini sinırlı tutmuştur. Yürütülen dersin çevrimiçi boyutunda öğrencilerin kendi ihtiyaçları doğrultusunda hiyerarşik rol dağılımları olmadan bilgi edinmeleri sürecine teknolojik araçlar ön ayak olmuşlarsa da, ortaya çıkan bir durum vardır ki, öğrenciler elektronik ortamda karşılarına çıkan ilk kaynağı güvenirliğini sorgulamadan elde etmiş ve eleştirel yaklaşmadan sadece kopyala-yapıştır yöntemi ile bilgiyi yapılandırmışlardır. Benzer şekilde, çevrimiçi ortamlarda gerçekleşen tartışma gruplarında da, öğrenciler birbirilerinin gönderilerini okumadan internette buldukları tüm bilgileri doğrudan "yapıştır" seçeneği ile sisteme yüklemişlerdir. $\mathrm{Bu}$ ise demokratik pedagojinin temel ilkelerinden olan diyalog ortamının oluşmasına bir engel teşkil etmiştir. $\mathrm{Bu}$ duruma daha dikkatli bakıldığında, ders sonunda yapılan röportajlarda öğrenciler sosyo-epistemolojik karakteristikleri ile ilgili olarak daha çok dinlemeye dayalı yani sözel yollarla bilgi edindiklerini belirtmişlerdir. Hâlbuki ders kapsamında tasarımlanan çevrimiçi ortamda sadece okuma ve yazmaya yönelik iletişim kanalları açıktır. Benzer şekilde, bilgi otoritesi olarak şimdiye kadar öğretmenleri esas aldıkları için Google gibi arama motorlarının ve arkadaşlarının foruma gönderdiği mesajların bir öğrenme biçimi haline gelmesi ve bilgi otoritesi olan öğretmenlerin yerini alması onlar için oldukça zor bir deneyimdir.

\section{TARTIŞMA VE SONUÇ}

$\mathrm{Bu}$ çalışmada demokratik eğitim söylemlerini teknoloji bağlamında yeniden değerlendirmek ve alanyazındaki tartışmaları tarihi bağlamda sunarak, demokratik eğitimin zaman içerisinde nasıl geliştiğini göstermek amaçlanmıştır. Daha sonra, bu tarihi dönemlerin son dilimine yani güncel gelişmelere değinilerek teknolojinin daha çok kuramsal boyutta kalan bir paradigmanın gerçekleşmesine ve bir iç dinamik sunma potansiyeline odaklanarak Sanal Öğrenme Toplulukları bağlamında alanyazındaki çekişmeli tartışmalar farklı görüşler açısından değerlendirilmiştir. 
Aşağıda sunulan tablo (Tablo 1), SÖT'lerin bazı temel bileşenleri üzerinden demokratik pedagojiyi sorgulayan eleştirel ve destekleyici yaklaşımların kısa bir özetini yansıtmaktadır.

Tablo 1. Sanal Öğrenme Topluluklarının (SÖT) bazı temel bileşenleri üzerinden demokratik pedagojiyi sorgulayan destekleyici ve eleştirel yaklaşımlar

\begin{tabular}{|c|c|c|c|}
\hline & & $\begin{array}{l}\text { Destekleyici } \\
\text { Yaklaşımlar }\end{array}$ & Eleştirel Yaklaşımlar \\
\hline \multirow{5}{*}{$\begin{array}{l}\text { SÖT } \\
\text { Temel } \\
\text { Bileşenleri }\end{array}$} & Kat1lım & Eşit katılım & Çoğunluğun tiranı \\
\hline & Özerklik & $\begin{array}{l}\text { Bileşenlerin SÖT çatısı } \\
\text { altında bağımsız } \\
\text { olmaları }\end{array}$ & $\begin{array}{l}\text { SÖT'lerin bir eğitim sistemine } \\
\text { bağlı olmaları }\end{array}$ \\
\hline & Sosyal eşitlik & $\begin{array}{l}\text { Teknolojik ortamın } \\
\text { özelliklerinin } \\
\text { kullanılmasıyla oluşan } \\
\text { sosyal eşitlik }\end{array}$ & $\begin{array}{l}\text { SÖT'lerde sosyal eşitliğin yüz } \\
\text { yüze ilişkilerin devamı olmas } 1\end{array}$ \\
\hline & Teknoloji & $\begin{array}{l}\text { Teknolojinin, diyaloga } \\
\text { dayalı etkileşimli ve } \\
\text { işbirlikçi öğretimi } \\
\text { destekleyici özelliği }\end{array}$ & $\begin{array}{l}\text { Teknolojinin eğitimi } \\
\text { demokratikleştirmede sosyo- } \\
\text { kültürel faktörlere bağımlılığ }\end{array}$ \\
\hline & $\begin{array}{l}\text { Ağlar ve } \\
\text { bağlantılar }\end{array}$ & $\begin{array}{l}\text { Ağların ve bağlantıların } \\
\text { bileşenleri bir araya } \\
\text { getirme, öğrenme ve } \\
\text { öğretimi yeniden } \\
\text { düzenleme işlevi }\end{array}$ & $\begin{array}{l}\text { Ağların ve bağlantıların } \\
\text { gözetlemeye dayalı } \\
\text { (surveillance) kontrol ve } \\
\text { denetime yol açma işlevi }\end{array}$ \\
\hline
\end{tabular}

Yukarıdaki tabloyu (Tablo 1) yorumlarken dikkate alınması gereken önemli bir nokta şudur ki alanyazındaki SÖT'lerin demokratik pedagojiyi gerçekleştirme potansiyelini sorgulatan bu görüşler iki farklı kutupta (SÖT'ler demokratik eğitimi destekler veya desteklemez gibi) değerlendirilmemelidir. $\mathrm{Bu}$ konuyu ele alan araştırmacılar, taraf tutarak genel olarak teknoloji destekli SÖT'lerin sadece bir yüzünü vurgulamaktan ziyade, görülen-görülmeyen farklı kuram ve uygulama boyutlarına dikkat çekme eğilimindedirler.

Buna göre, kısaca, katılım, özerklik ve soysal eşitlik gibi pedagojik değerler üzerine kurulu olan ve günümüzde internet temelli açıköğretim sistemlerinde yaygınlaşarak eğitim sisteminde yer alan sanal öğrenme toplulukları, eğitimin demokratikleştirilmesi açısından bir potansiyel arz etmektedir. Ancak, bazı araştırmacıların da vurguladıkları gibi böylesine bir söylem deterministik bir yaklaşım olacaktır ve özellikle teknolojinin her derde deva olabileceği inancı 
yanıltıcı bir çözüm arayışıdır. Çünkü bu tür oluşumlar bir ölçüde tasarım faktörüne bağlı olarak anlamlandırılan bir yapıdadır.

Bu noktada, SÖT ve demokrasi ilişkisini sorgularken bütün bu alanyazındaki tartışmaların bir potada eritilebileceği en önemli noktalardan biri de tasarımdır. Somut bir örnek vermek gerekirse, bir tasarımcı, sanal öğrenme toplulukları ile verilen bir eğitim planlarken, eğitsel etkinlikler çerçevesinde öğretmen ve öğrencinin eşit söz sahibi olduğu ve dersin akışına birlikte karar verdikleri bir sanal ortam tasarlayabilir. Daha somut olarak, internet ile sunulan bir açıköğretim sisteminde forumlar aracılığı ile tartışma ortamı sunulabilir ve katılımcılar (öğretmen ve öğrenciler) tartışarak bu ortamlarda dersin akışına ilgi ve istekleri doğrultusunda karar verebilir. Burada, öğretmenler 'öğretici' değil daha çok 'kolaylaştırıcı' rolündedir ve öğrencilerin çoğunluk tarafindan paylaşılan bir öğretim hedefine ulaşmasına yardımcı olur (Lewis ve Allan, 2005). Ancak, ortak değerlere ulaşmak demek aynı zamanda çoğunluğun azınlık üzerindeki bastırıcı gücü yani 'çoğunluğun tiranı' (Ferreday ve Hodgson, 2010) anlamına da gelebilir. Bu noktada, öğretmenler (kolaylaştırıcılar) tarafından bireysel farklılıkları yaşatan kişisel öğrenme etkinlikleri düzenlenebilir. Yine bu tartışma forumları aracılı̆̆ 1 ile öğrencilerin bireysel olarak aktif bir şekilde belirlenen bir konu çerçevesinde araştırma yapıp işbirliği ile sosyal bilgi yapılandırmaları sağlanabilir. Öğrencilerin teknolojik araçlardan faydalanarak bu şekilde öğrenmeleri, yani örneğin tartışma forumlarından yararlanarak kendi ilgi, istek ve iradeleri ile konu belirleyip gerektiğinde teknoloji destekli iletişim araçları ile yardım alarak araştırma yapmaları ve de birbirleri ile tartışarak bilgi yapılandırmaları, teknolojinin otoriteden ve hiyerarşik ilişkilerden bağımsız bir öğretimi destekleme potansiyeline işaret etmektedir (Garrison, 1997). Bu noktada, tartışma forumları ve aynı anda çok yönlü iletişimin sağlanabildiği videokonferans ve sohbet ortamları (chat room) gibi teknolojik araçlar işbirlikçi diyalog ortamlarına platform sağlayan ve demokratik eğitimi destekleyen bir hizmet verebilir (Boyd, 1987; Garrison, 1997). Ancak unutulmamas1 gereken bir nokta da şudur ki bu araçlar aynı zamanda gerçekleşen bütün yazışmaları ve kullanıcının sisteme giriş çıkış saati ve site içindeki gezinimlerini kayit altına alabilen sistemlerdir. Teknolojinin gözetlemeye dayalı kontrol ve denetim amaçlı (Conlon, 2000; 
Warschauer \& Lepeintre, 1997) kullanılmaması için bu ortamdaki yetkililerin kayıt altında tutulan bu bilgilere ulaşmalarının engellenmesi ve bu bilgilerin öğrenciler aleyhinde kullanılmaması gerekmektedir.

Tasarım başlığ 1 altında ele alınması gereken bir diğer konu da teknolojinin sosyo-kültürel değerlerden bağımsız olmadığı gerçekliğidir (Levy, 2004, Mantovani, 1994; Öztürk, 2011). Bu sosyokültürel değerler, eğitim bileşenlerinin (öğretmen, öğrenen ve yönetici gibi) epistemolojik karakteristiklerinden, bağlı oldukları kurum (üniversite veya okullar gibi) ve ülkenin eğitim sisteminin etkilendiği eğitim paradigmasına kadar değişen bir yelpazede ele alınabilir. Teknoloji destekli Sanal Öğrenme Ortamlarının sosyo-kültürel bağlamda irdelenmesi açısından Öztürk (2011) yaptığı tez çalışmasında kapsamlı sonuçlara yer vermiştir. Buna göre, Türkiye'de bir yüksek öğretim kurumunda bir akademik dönem boyunca sanal öğrenme topluluğu ilkeleri ile bir ders tasarımlamış ve bu araştırmada STÖ üyelerini oluşturan 33 üçüncü sınıf lisans öğrencisi ile deneyimlerini paylaşmak ve tartışmak üzere akademik dönemin bitimine doğru odak grubu toplantıları yapmıştır. Bu toplantılarda öğrencilerin sıklıkla dile getirdikleri nokta, sanal öğrenme topluluğunun idealize ettiği türden bir özgürleştirici eğitime henüz hazır olmadıklarıdır. Bunun altında yatan en önemli sebep, şimdiye kadar aldıkları eğitimin ezberci ve öğretmen odaklı bir eğitime dayalı olduğu ve bu nedenden ötürü epistemolojik açıdan bilgiye ulaşmada ve değerlendirmede sıkıntı yaşadıklarıdır. Örneğin, sosyal çevrelerinden (aile vs.) hiyerarşik bir yapıda öğrenilirlerken (yaşlılara sayg1 duyarak öğrenme, cinsiyete dayalı öğrenme gibi), hiyerarşinin yıkıldığı ve kendi gücüne dayalı olarak öğrenmenin gerçekleştiği bir ortam öğrencileri zorlamıştır. Buna paralel olarak, Öztürk (2011) dersin öğretmeni ile yaptığı görüşmelerde de benzer sonuçlar elde etmiştir. Buna göre, dersin öğretmeni dersi çoklu kaynaklar üzerinden tartışmak istediğinde hem öğrencilerin okuma alışkanlıklarının yeterli olmaması, hem de bu kaynakların kütüphanede bulunmaması durumunda öğrencilerin kaynakları satın alacak ekonomik koşullarının olmaması nedeniyle derste kaynak önermeme eğiliminde olduğunu belirtmiştir. $\mathrm{Bu}$ noktada, daha önceden de belirtildiği gibi SÖT ile öğrenmede tasarım etkeni önemli bir yere sahiptir. Buna göre, öğrencilerin epistemolojik karakteristiklerinin çelişmesi ve de geçmiş 
öğrenme deneyimleri ile demokratik eğitimin sunduğu öğrenme ortamlarının çelişmesi gibi durumların yapılacak olan tasarıma bağglı olarak dersin ilk haftalarında verilebilecek pedagojik eğitim ile yani öğrencilerin tartışarak ve benimseyerek özgürleştirici bir öğretimi kabullenmesi ile aş1labilir.

Ancak, önemli bir nokta da şudur ki her ne kadar SÖT’ler kendi içinde özerk olabilse de, bağlı oldukları kurum ve eğitim sisteminden farklı hareket etmeleri her zaman mümkün olmayabilir. Bununla ilgili olarak, Öztürk (2011) yaptığı çalışma çerçevesinde SÖT ile ders yürüten öğretmen ile yaptığı görüşmede, dersin öğretmeninin çalıştığ1 yüksek öğretim kurumunun öngördüğü şekli ile ders yükünün oldukça fazla olması ve dersin değerlendirmesi için öğretmene tanınan sınırlı zaman gibi faktörlerin demokratik bir eğitimin gerektirdiği şartlar ile çeliştiğini bulgulamıştır. Aynı şekilde, SÖT'ün bağlı olduğu yüksek öğretim kurumu, bir takım internet sitelerinin ve internet uygulamalarının bazı gerekçeler ile yerleşke içinde ulaşılmasını yasaklamış ve bu öğrencilerin bağımsız ve tarafsız bilgiye ulaşması ile varlığını sanal ortamda devam ettirebilmeleri açısından engelleyici bir durum oluşturmuştur. Dolayısıyla, sanal öğrenme toplulukları her ne kadar kendi içinde özerk oluşumlar olabilse de SÖT'lerin bağlı olduğu kurumlar çerçevesinde ele alındığında bu özerk yapılar sorgulanabilir hale gelmektedir (Boud, 1988).

Ancak, sunulan bu çerçeve büyütülüp öğrenci, öğretici, yönetici ve kurumların da içinde bulunduğu eğitim sistemi değerlendirildiğinde, küresel düzeydeki eğitim paradigmalarındaki değişimin SÖT'leri destekleyecek nitelikte gelişim seyretmekte olduğu görülebilir. Daha somut olarak, son yıllarda tartışıla gelen bireyi merkeze alan eğitim anlayışı, öğretmen odaklı eğitimden öğrenci odaklı eğitime geçiş ve ezberci eğitimden yapılandırmacı eğitime geçiş gibi gelişmeler eğitimde bir dönüşüme işaret etmektedir (Brown, 2005). Bu dönüşümler demokratik eğitimin değerleri ile paralellik göstermektedir. Dolayısıyla, SÖT'ler kendi içinde özerk olabilirken, bağlı oldukları kurum ve eğitim sistemlerinden bağımsız hareket edememeleri zaman içerisinde eğitim paradigmalarındaki devinim ile değişebilecek bir durumdur. 


\section{KAYNAKLAR}

Boud, D (1988). Moving Towards Autonomy. (Editör: D. Boud). Developing Student Autonomy in Learning (ikinci baskı) içinde (ss.17 - 39). Londra: Kogan Page.

Boyd, G. M. (1987). Emancipative educational technology. Canadian Journal of Educational Communication, 16 (2), 167 - 172.

Brookfield, S. D. (1994). Tales from the Dark Side: a Phenomenography of Adult Critical Reflection. International Journal of Lifelong Education, 13(3), 203 216.

Brown, T. H. (2005). Beyond constructivism: Exploring future learning paradigms. Education Today, (2), $1-11$.

Bruffee, K.A. (1999). Collaborative learning: Higher education, interdependence, and the authority of knowledge (ikinci bask1). Baltimore, MA: Johns Hopkins University Press.

Conlon, C. (2000). Visions of change: information technology, education and postmodernism. British Journal of Educational Technology, 31 (2), 109-116.

Cooke, B. \& Kothari, U. (2001). Participation: The New Tyranny? Londra: Zed Books.

Dewey, J. (1903). Democracy in Education. The Elementary School Teacher, 4 (4).

Dewey, J. (1916). Democracy and Education. New York: The Macmillan Company.

Dewey, J. (1938). Experience and Education. New York: Kappa Delta Pi.

Dewey, J. (1939/1991) Creative Democracy - the Task Before Us. John Dewey: The Later Works, 1925-1953, (14), 224-230 Carbondale, IL: Southern Illinois University Press.

Dillenbourg, P. (1999). Collaborative Learning. Cognitive and Computational Approaches. Amsterdam; New York : Pergamon.

Ferreday, D., \& Hodgson, V. (2010). Heterotopia in Networked learning: Beyond the shadow side of participation in learning communities. Lancaster University Management School Working Paper. 21 Şubat 2011 tarihinde http://eprints.lancs.ac.uk/49033/1/Document.pdf internet adresinden erişilmiştir.

Ford, L., Branch, G., \& Moore, G. (2008). Formation of a virtual professional learning community in a combined local and distance doctoral cohort, $A A C E$ Journal, 16(2), 161-185.

Freire, P. (1970). Pedagogy of the Oppressed. Harmondsworth: Penguin Books.

Freire, P. (1998). Pedagogy of freedom. Ethics, Democracy, and civic courage. US: Rowman \& Littlefield Publishers.

Garrison, D. R. (1997). Computer conferencing: the post-industrial age of distance education. Open Learning: The Journal of Open, Distance and e-Learning, 12 (2), $3-11$.

Gore, J. M. (1999). On the limits to empowerment through critical and feminist pedagogies. (Editörler: D. Carlson, \& M. W. Apple). Power/Knowledge/Pedagogy: The Meaning of Democratic Education in Unsettling Times (ss. 271 - 288). Boulder, CO: Westview Press. 
Giroux, H. A. (1992). Border crossings: cultural workers and the politics of education. New York: Routledge.

Hine, C. (2000). Virtual Ethnography. Londra: Sage Publications.

Hodgson V. (2002). Issues for democracy and social identity in CMC and Networked Learning. (Editörler: C. Steeples \& C. Jones). Networked Learning: Perspectives and Issues içinde (ss. 229-242). Berlin: Springer.

Hodgson, V., \& Watland, P. (2004). Researching Networked Management Learning. Management Learning, 35(2), 96 -116.

Hodgson, V., \& Reynolds, M. (2005). Consensus, difference and 'multiple communities' in networked learning. Studies in Higher Education, 30 (1), 11 24.

Hodgson, V. (2008). Learning Spaces, context and auto/biography in online learning communities. Journal of Web Based Communities, 4(2), 159-172.

Jones, S.G. (1995). Understanding community in the Information Age. (Editör: S. G. Jones). Cybersociety: Computer-Mediated communication and community (ss. 10 -35). Thousand Oaks: CA: Sage Publications.

Knight, T., \& Pearl, A. (2000). Democratic Education and Critical Pedagogy. The Urban Review, 32 (3), 197-226.

Kowch, E., \& Schwier, R. (1997). Characteristics of Technology-Based Virtual Learning Communities. University of Saskatchewan, 27 Şubat 2011 tarihinde http://www.usask.ca/education/coursework/802papers/communities/communiti es.htm internet adresinden ulaşılmıştır.

Lankshear, C., Peters, M., \& Knobel, M. (1996). Critical pedagogy and cyberspace. (Editörler: H. A. Giroux ve diğerleri). Counternarratives: Cultural Studies and Critical Pedagogies in Postmodern Spaces (ss.149 -189). NewYork: Routledge

Levy, P. (2004). A methodological framework for practice-based research in networked learning. (Editörler: P. Goodyear, S. Banks, V. Hodgson \& D. McConnell). Advances in research on networked learning. ComputerSupported Collaborative Learning (ss. 43-66). Londra: Kluwer.

Levy, P. (2007). Towards a community of inquiry for inquiry-based learning: a CETL perspective. Practising the Scholarship of Teaching and Learning, Proceedings of the SoTL 6th Annual International Conference, City University, Londra, 18-19 Mayis 2006.

Lewis, D., \& Allan, B. (2005). Virtual Learning Communities: A guide for practitioners. Berkshire: Open University Press.

Mantovani, G. (1994). Is computer-mediated communication intrinsically apt to enhance democracy in organisations? Human Relations, 47, 45-62.

McConnell, D. (2000). Implementing Computer-supported Cooperative Learning. (ikinci bask1). Londra: Kogan Page.

McConnell, D. (2005). Examining the Dynamics of Networked E-Learning Groups and Communities. Studies in Higher Education, 30 (1), 25-42.

McConnell, D. (2006). E-Learning Groups and Communities. England and New York: The Society for Research into Higher Education \& Open University Press.

Neill, A. S. (1962). Summerhill: a radical approach to education. Londra: Gollancz. 
Neill, A. S. (1992). The New Summerhill. Londra: Penguin Books.

Pearl, A., \& Knight, T. (1998). The Democratic Classroom: Theory to Guide Practice. Cresswell, NJ: Hampton Press.

Pedler, M. (1981). Developing the learning community. (Editörler: Tom Boydell \& Mike

Pedler). Management self-development: concepts and practices (ss. 68 - 84). Aldershot: Gower Publishing Company Limited.

Reynolds, M. (1999). Grasping the Nettle: Possibilities and Pitfalls of a Critical Management Pedagogy. British Journal of Management, 9, 171-184

Reynolds, M., \& Hodgson, V. (2002, Mart). Network learning and ideas of community. Third International Networked Learning konferansinda sunulan bildiri, Sheffield, UK.

Riel, M. (1995). Cross-classroom collaboration in global learning circles. (Editör: S. Leigh Star). The Cultures of Computing (ss. 219-242). Oxford: Blackwell Publishers/The Sociological Review.

Schwier, R. A. (2001). Catalysts, emphases, and elements of virtual learning communities. Implications for Research and Practice. The Quarterly Review of Distance Education. 2(1), 5-18.

Schwier, R. A. (2007). Did We Become a Community? Multiple Methods for Identifying Community and Its Constituent Elements in Formal Online Learning Environments. (Editörler: N. Lambropoulos \& P. Zaphiris). UserCentered Design of Online Learning Communities (ss. 29 - 53). Hershey: Information Science Publishing.

Schwier, R.A. (2011). The elusive metaphor of virtual learning communities. (Editör: G. Anglin). Instructional technology: Past, present, future (3. bask1). Englewood Cliffs, CO: Libraries Unlimited

Smith, R. O. (2008). The paradox of trust in online collaborative groups. Distance Education, 29 (3), 325-340.

Sorensen, E. K., \& Murchu, D. (2004). Designing online learning communities of practice: A democratic perspective. Journal of Educational Media, 29(3), 189 -200 .

Öztürk, H. T. (2011). Conflict in Virtual Learning Communities in the Context of a Democratic Pedagogy. Yayımlanmamış Doktora Tezi, Lancaster University, UK.

Warschauer, M., \& Lepeintre, S. (1997). Freire's dream or Foucault's nightmare: Teacher-student relations on an international computer network. (Editörler: R. Debski, J. Gassin, \& M. Smith). Language Learning Through Social Computing içinde (ss. 67-89). Parkville, Avustralya: Applied Linguistics Association of Australia.

Wenger, E. (1998). Communities of Practice. Learning, meaning and identity. Cambridge, U.K. ; New York, N.Y: Cambridge University Press. 